Cahiers $d u$ MONDE RUSSE

\section{Cahiers du monde russe}

Russie - Empire russe - Union soviétique et États indépendants

$49 / 4 \mid 2008$

Destins individuels et terreur. Jeunesse dans la société post-stalinienne

\title{
Katerina Clark, Evgeny Dobrenko et al., Soviet Culture and Power
}

\section{Gábor T. Rittersporn}

\section{(2) OpenEdition}

1 Journals

Édition électronique

URL : https://journals.openedition.org/monderusse/6952

DOI : $10.4000 /$ monderusse. 6952

ISSN : $1777-5388$

Éditeur

Éditions de l'EHESS

\section{Édition imprimée}

Date de publication : 28 décembre 2008

Pagination : 766-769

ISBN : 978-2-7132-2197-2

ISSN : $1252-6576$

Référence électronique

Gábor T. Rittersporn, « Katerina Clark, Evgeny Dobrenko et al., Soviet Culture and Power », Cahiers du monde russe [En ligne], 49/4 | 2008, mis en ligne le 24 décembre 2009, consulté le 02 septembre 2022. URL : http://journals.openedition.org/monderusse/6952 ; DOI : https://doi.org/10.4000/ monderusse.6952

Ce document a été généré automatiquement le 2 septembre 2022.

Tous droits réservés 


\title{
Katerina Clark, Evgeny Dobrenko et al., Soviet Culture and Power
}

\author{
Gábor T. Rittersporn
}

\section{RÉFÉRENCE}

Katerina CLARK, Evgeny DOBRENKO with Andrei ARTIZOV and Oleg NAUMOV, Soviet Culture and Power. A History in Documents, 1917-1953. New Haven, CT-Londres : Yale University Press, 2007, xxx +545 p. (Annals of Communism).

1 Voici un recueil de sources que Clark et Dobrenko commentent avec talent. Ajoutons tout de suite qu'ils n'ont pas fait grand-chose pour réunir les matériaux. À partir d'une publication de 559 documents que les compilateurs russes avaient intitulés : « Le pouvoir et l'intelligentsia artistique », ils en ont choisi 181 pour présenter leur analyse.

2 Bien sûr, lectio est selectio. Reste à savoir, cependant, s'il est judicieux de s'en remettre à une sélection effectuée par d'autres à partir d'une masse énorme de documents. On peut bien sûr donner des instructions précises, vérifier et compléter le travail en fonction de ses propres conceptions. Mais c'est précisément ce que Clark et Dobrenko ont évité de faire.

Ils ont fait confiance à Andrei Artizov et à Oleg Naumov, ou plutôt à leur travail, car ils n'ont aucunement participé aux recherches des deux Russes. Les sources que ces derniers ont éditées proviennent de diverses instances du Comité central et de la police secrète. L'anthologie embrasse les 36 années qui s'étendent de la révolution jusqu'à la mort de Stalin. Un grand nombre de documents proviennent des archives du Politbjuro et de la Sécurité d'État, qui ne sont ouvertes, précisons-le, qu'à quelques chercheurs russes.

Les critères de sélection de Naumov et Artizov n'apparaissent pas clairement. Les documents ne sont pas commentés. Au-delà de leur localisation et d'un certain nombre de notes insuffisantes, les compilateurs se sont contentés de faire marcher la photocopieuse. Tout ce qu'on apprend des cinq pages d'introduction est qu'ils voulaient publier uniquement des documents rédigés ou lus par les dirigeants de l'État-parti et par 
la direction de la police politique. Pour le reste, les textes sont reproduits en ordre chronologique. Le découpage en chapitres est un leurre car il ne modifie en rien la chronologie.

5 Beaucoup de matériaux sont intéressants: décisions des autorités concernant la politique culturelle, rapports sur des œuvres et sur des auteurs, lettres adressées aux dirigeants du régime (éventuellement accompagnées de réponses) et documents qui montrent l'intervention de hauts dignitaires et de Stalin dans la vie artistique et dans la création des écrivains, cinéastes, compositeurs et dramaturges. Architecture et arts plastiques sont pratiquement absents. Nombre de pièces sont peu significatives: que viennent faire là des résolutions autorisant la célébration d'une date-anniversaire de Balzac ou de Chopin à Moscou et d'une épopée populaire en Bouriatie... ou une décision en huit mots qui nous apprend que le Politbjuro n'avait rien contre la visite de Romain Rolland en URSS ? Certains thèmes apparaissent brièvement, d'autres sont traités en détail. Voilà donc le volume russe.

Quant à Clark et Dobrenko, ils ont organisé leur sélection en sections plus ou moins cohérentes. Les trois parties de l'ouvrage couvrent les trois décennies postrévolutionnaires. Chacune d'elle est divisée en chapitres thématiques. Ceux-ci traitent d'un large éventail de questions qui vont de l'intention des autorités de supprimer le théâtre Bol'šoj au rôle de Gor'kij dans la vie littéraire, de l'attitude du parti à l'égard des intellectuels taxés d'antisoviétisme au sort des organisations d'écrivains, de la campagne contre le «formalisme » à la ždanovščina, des élucubrations de Stalin au sujet d'œuvres littéraires et cinématographiques à sa correspondance avec Šolohov, Bulgakov, Gor'kij et Pasternak.

7 On apprend beaucoup de choses, même si cela ne concerne pas forcément les rapports entre la culture soviétique et le pouvoir. C'était pourtant bien cela qu'annonçait le titre. Or, c'est à la surveillance des artistes et au contrôle de la littérature et des arts par l'Étatparti que se sont intéressés Artizov et Naumov. Si bien que Clark et Dobrenko ont dû faire usage de matériaux qui portent davantage sur les démarches policières du parti que sur la culture en tant que telle. Il est indéniable que le régime soviétique a exercé une pression extraordinaire sur les artistes, incontestable que les lettres et les arts ont énormément souffert sous les bolcheviks. Reste à savoir, néanmoins, si la politique culturelle est à même de tout expliquer. Elle dit bien ce qui ne pouvait pas être fait et ce que pensaient les politiciens les plus éminents du régime et leur coryphée, Stalin. Mais elle est loin de rendre compte de la culture en tant que telle.

Car, même si les contraintes politiques ont joué un rôle crucial, on ne peut prétendre saisir la culture soviétique en observant leur jeu uniquement au sommet du régime et dans les milieux de l'élite artistique. Clark et Dobrenko ne se laissent pas seulement piéger par une documentation qu'ils n'ont pas choisie - ils sont en outre prisonniers de la conception soviétique du rapport entre pouvoir et culture: le premier est strictement réglementé par le Kremlin et la seconde est une culture officielle remarquablement malléable ou, éventuellement, une culture d'opposition. Le champ de vision de nos auteurs est trop restreint par celui d'Artizov et Naumov pour qu'ils s'aventurent au-delà de la culture produite par des artistes plus ou moins en vue.

9 Pourtant, pouvoir et culture se rencontraient bien au-delà des officines du Comité central et du haut commandement de la police secrète. De toute évidence, Artizov et Naumov ne s'étaient pas aperçus, aux archives de la police politique, de l'intérêt que les organes de sécurité portaient, par exemple, aux petits cercles de littérateurs amateurs 
qui n'étaient pas encadrés par des institutions de l'État-parti et qui fleurissaient un peu partout dans le pays. On a quelque raison de supposer que la curiosité de la police pour leurs écrits créait un champ où la petite et la grande politique croisaient la culture, même si cette dernière ne ressortissait pas nécessairement à ce qu'on estimait comme littérature en haut lieu. Mais malgré tout, cette documentation renferme des renseignements précieux sur ce que la haute culture signifiait pour le public le plus passionné et sur l'appréciation par le pouvoir de pratiques créatrices qui n'étaient guère faciles à contrôler.

Il serait erroné de supposer que ces pratiques étaient inévitablement hostiles au régime. La plupart du temps, celles qu'on est tenté d'élever au statut de dissidence au sein de l'élite artistique ne l'étaient pas non plus. Une étude comparée des deux sphères de créativité et de la façon dont les autorités les voyaient et les traitaient serait indispensable pour appréhender mieux la culture soviétique que l'image qu'en donnaient les bolcheviks et les auteurs du volume russe - et que Clark et Dobrenko reprennent à leur compte.

On n'insistera jamais assez là-dessus : l'interaction du pouvoir soviétique et de la culture est incompréhensible si l'on ne tient pas compte de la réaction à la culture officielle d'une société assez peu soucieuse des débats byzantins sur le réalisme socialiste. Par exemple, la véritable figure-culte du public, parmi les poètes soviétiques, n'était ni Pasternak, ni Ahmatova, ni Mandel'štam, quelle que soit leur éminence ni même Dem'jan Bednyj ou Aleksandr Bezymenskij. C'était Sergej Esenin, jusqu'aux années 1960 environ. Nombre de ses œuvres ne furent pas republiées, longtemps après sa mort. Mais elles circulaient sous forme manuscrite, étaient citées dans des lettres et dans des journaux intimes, ornaient les albums des jeunes filles, se transformaient selon le modèle de la tradition orale et incitaient des fidèles à imiter ses vers ainsi qu'à s'inspirer de son train de vie bohème, jusqu'à fonder des véritables clubs de suicidaires qui se réclamaient de lui. Le phénomène ne faisait pas moins partie de la culture soviétique que l'Union des écrivains. Il inquiétait les autorités : où trouver de meilleures sources pour illustrer leurs réactions qu'aux archives de la police secrète?

Autre exemple. La littérature officielle était très lue, entre autres parce qu'elle tenait le haut du pavé. Malgré tout, elle n'était pas la seule lecture du public. Au milieu des années 1930, les Izvestia sonnèrent l'alarme à propos de l'engouement, surtout chez les jeunes, pour les romans bon marché d'avant la Révolution mettant en scène toutes sortes de bandits, détectives, aventuriers ou encore des histoires d'amour platoniques ou charnelles. Les documents du Komsomol et du parquet suggèrent que le pouvoir cherchait à répondre. Comment classer cette culture littéraire et celle de la eseninščina par rapport au paradigme que les autorités s'évertuaient à imposer? Pourquoi refuser d'explorer des documents qui montrent l'intervention du pouvoir dans la sphère culturelle au sens large?

Du reste, c'est le pouvoir lui-même qui, après-guerre, a envahi les écrans avec l'équivalent cinématographique des romans noirs et roses. Il s'agit des films saisis dans l'Allemagne vaincue et connus sous l'appellation de "films trophées». Ils ont subi des coupures et un doublage pour les rendre compatibles avec les normes soviétiques. Artizov et Naumov se contentent de publier trois listes de titres (qui sont loin de contenir tout ce qui était autorisé à sortir). Clark et Dobrenko signalent simplement que ces films inondaient les cinémas. C'est vrai : ces pellicules faisaient fureur. Les histoires édifiantes, aventureuses, galantes et surtout les opérettes viennoises, pseudo-viennoises 
et leur star, Marika Rökk, éclipsaient toute la production et tous les acteurs soviétiques. Après la guerre, la grande vedette nazie n'avait certainement pas autant d'admirateurs dans le monde tout entier que dans le pays des Soviets. Si bien que l'un de ses films cultes a été réédité en Russie post-soviétique sous forme de DVD, bien entendu dans sa version soviétisée.

Clark et Dobrenko ont sans doute raison de montrer un Stalin dans son rôle de censeur suprême de scénarios, prenant soin d'imposer sa précieuse collaboration s'il le jugeait nécessaire. Mais qu'en est-il des films trophées? Le vožd' aurait-il oublié de s'en préoccuper? Qui les choisissait et selon quels critères? Qui avait autorité sur leur remaniement? Qu'en attendait un pouvoir soucieux d'inculquer au public des valeurs quelque peu éloignées du message qu'ils véhiculaient, même sous une forme bolchevisée? Faut-il négliger ces questions sous prétexte que Artizov et Naumov ne s'intéressent qu'aux trois listes sur lesquelles ils sont tombés parmi les décisions du Politbjuro?

Il peut paraître injuste de reprocher à des auteurs ce qu'ils n'ont pas fait au lieu de passer en revue ce qu'ils ont accompli. Mais est-ce un tort d'espérer qu'ils sortent de la logique du pouvoir qu'ils veulent expliquer? Est-ce trop demander que de voir restituée l'épaisseur de l'histoire d'une culture que l'on ne saurait réduire aux arts officiels ni à ce que comprennent ceux de nos contemporains russes qui sont restés dans la tradition soviétique? On attendrait plus de perspicacité de la part de Clark et de Dobrenko qui sont les pionniers de nouvelles interprétations de la culture soviétique.

entications des documents sont intéressantes, mais laissent perplexe quant au public auquel elles s'adressent. Car les commentaires documentent les connaissances des spécialistes, mais ne sont pas aisément accessibles au grand public qui est pourtant visé dans la préface, d'où le souci d'assortir l'ouvrage de notices biographiques.

17 L'honnête homme risque d'être déçu. Que d'« écrivains soviétiques ", « metteurs en scène soviétiques » ou encore " poètes soviétiques » sans plus de précision, alors qu'il est assez évident d'après le texte des documents qu'il s'agit d'écrivains et d'artistes. Prokofiev a droit au titre de " compositeur soviétique majeur ", tandis que Šostakovič se contente du qualificatif de "grand». En tout état de cause, peu de personnalités atteignent au statut d'André Malraux. On apprend qu'il aurait été au fait des crimes de Stalin, mais soutenait le régime soviétique dans les années 1930, et surtout qu'il était « romancier, aventurier, historien de l'art et homme d'État. ».

18 Ceux qui s'intéressent aux mesures vexatoires que les artistes soviétiques eurent à subir et aux stratégies de l'État-parti pour contrôler les milieux des arts et des lettres peuvent faire leur propre sélection dans le recueil d'Artizov et de Naumov, ou aller prospecter ailleurs. Mais une bonne édition de sources élucidant les relations fort complexes entre régime et culture en URSS reste à faire. Espérons que les rédacteurs du futur volume auront accès aux mêmes archives que celles que les auteurs russes ont dépouillées. Espérons également qu'ils soient aussi familiers de la culture soviétique que Clark et Dobrenko. Qui sait, peut-être ces derniers auront-ils l'occasion de rattraper ce rendezvous manqué? 